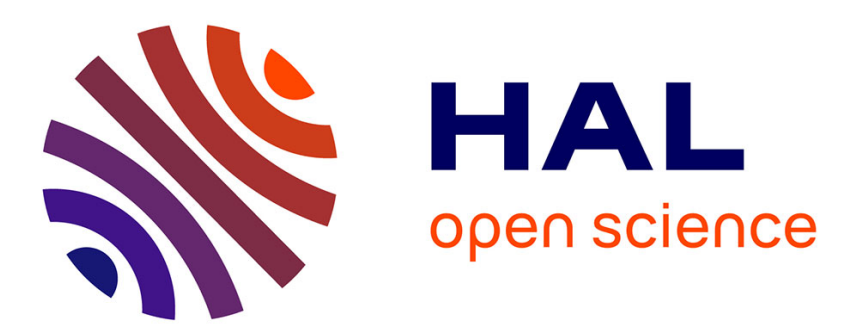

\title{
VIOLENT COLLISIONS BETWEEN IONS AS HEAVY AS KRYPTON AT GANIL AND GSI
}

\author{
G. Rudolf
}

\section{To cite this version:}

G. Rudolf. VIOLENT COLLISIONS BETWEEN IONS AS HEAVY AS KRYPTON AT GANIL AND GSI. International Conference on Heavy Ion Nuclear Collisions in the Fermi Energy Domain, 1986, Caen, France. pp.C4-351-C4-360, 10.1051/jphyscol:1986438 . jpa-00225804

\section{HAL Id: jpa-00225804 https://hal.science/jpa-00225804}

Submitted on 1 Jan 1986

HAL is a multi-disciplinary open access archive for the deposit and dissemination of scientific research documents, whether they are published or not. The documents may come from teaching and research institutions in France or abroad, or from public or private research centers.
L'archive ouverte pluridisciplinaire $\mathbf{H A L}$, est destinée au dépôt et à la diffusion de documents scientifiques de niveau recherche, publiés ou non, émanant des établissements d'enseignement et de recherche français ou étrangers, des laboratoires publics ou privés. 


\title{
VIOLENT COLLISIONS BETWEEN IONS AS HEAVY AS KRYPTON AT GANIL AND GSI
}

\author{
G. RUDOLF
}

\author{
Centre de Recherches Nucléaires, BP 20 CR, F-67037 strasbourg \\ Cedex, France
}

\begin{abstract}
Résumé - Des résultats rêcents obtenus pour des collisions violentes entre un faisceau de masse élevée $(A \succsim 100)$ et des cibles de masse comparable sont exposés. Jusqu'à $20 \mathrm{MeV} / \mathrm{u}$, le mécanisme est essentiellement celui des collisions profondêment inélastiques, bien que certaines dêviations apparaissent. Au-dessus de $20 \mathrm{MeV} / \mathrm{u}$, certaines données sont interprétées dans le cadre d'un modèle participant-spectateur, mais en tenant compte des effets de champ moyen qui restent très importants. A 35 et $44 \mathrm{MeV} / \mathrm{u}$, ces mécanismes permettent d'atteindre des températures telles que la multifragmentation devient possible.
\end{abstract}

Abstract - Data from violent collisions between heavy $(A \gtrsim 100)$ beams and targets of comparable mass are reviewed. The deep-inelastic mechanism dominates up to $20 \mathrm{MeV} / \mathrm{u}$, although some departures are already noticed. Above $20 \mathrm{MeV} / \mathrm{u}$, some data have been interpreted in the frame of a participantspectator model, but taking in account mean field effects which are still important. At 35 and $44 \mathrm{MeV} / \mathrm{u}$, such mechanisms allow to reach temperatures where the multifragmentation becomes possible.

\section{I - INTRODUCTION}

Since heavy ion beams have become available, two bombarding energy regions have mainly been explored: below $\mathrm{E} / \mathrm{A}=10 \mathrm{MeV} / \mathrm{u}$ where one observes collective phenomena, and above $\mathrm{E} / \mathrm{A}=100 \mathrm{MeV} / \mathrm{u}$ where nucleon-nucleon interactions dominate. The intermediate energy region has only recently begun to be investigated. Projectiles with mass $A \geq 100$ can be accelerated at GSI $(E / A<20 \mathrm{MeV} / \mathrm{u})$ and at Ganil $(\mathrm{E} / \mathrm{A}<50 \mathrm{MeV} / \mathrm{u}$ for such heavy beams).

The very first results obtained at Ganil with a $\mathrm{Kr}$ beam showed events indicative of a tremendous relaxation (1) : indeed on $1 \mathrm{y}$ fragments with sma11 $\mathrm{z}$ values and low velocities had been observed in the $\mathrm{Kr}+\mathrm{Au}$ reaction at $35.5 \mathrm{MeV} / \mathrm{u}$ (Figs, 1 and 2). These data had been measured at angles larger than the grazing angle.

They appeared completely different from the first results which had been obtained previously with an $\mathrm{Ar}$ beam (2) : in the $\mathrm{Ar}+\mathrm{Ni}$ and $\mathrm{Au}$ reactions at $44 \mathrm{MeV} / \mathrm{u}$, fragments with 2 values equal to or smaller than the beam one and velocities close to that of the projectile dominated the energy spectra measured at $3^{\circ}$.

Since than, data measured over a broad angular range showed that the difference is much less dramatic. For example, Fig.3 illustrates that, in the $\mathrm{Kr}+\mathrm{Au}$ reaction at $44 \mathrm{MeV} / \mathrm{u}$, fragmentation-type events as well as fragments relaxed in $z$ and velocity are emitted (3).

If no difference between $\mathrm{Kr}$ and $\mathrm{Au}$ induced reactions existed, the $\mathrm{Ar}$ beam would be, at Ganil, more attractive than the $\mathrm{Kr}$ one : indeed, $\mathrm{Ar}$ can be accelerated up to $60 \mathrm{MeV} / \mathrm{u}$, while $\mathrm{Kr}$ only up to $44 \mathrm{MeV} / \mathrm{u}$. Moreover, the $\mathrm{Kr}$ beam was not, until recently, of the "push button" type, although of good quality.

The aim of this paper is to explain why experimentalists prefer occasionally $\mathrm{Kr}$ or other mass 100 beams : the best way to do this is to present some results obtained with these beams. The alm of my introduction - emphasizing the difference between the very first data gained with $\mathrm{Ar}$ and $\mathrm{Kr}$ projectiles - was to indicate you which is the main philosophy of the paper: mass 100 ions induced reactions are 


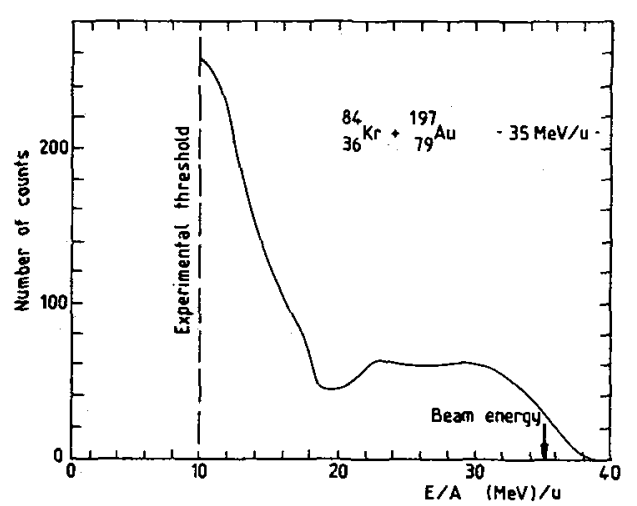

Fig.1 - Kinetic energy per nucleon of all the products with $E / A>10 \mathrm{MeV} / \mathrm{A}$ (from Ref.1).

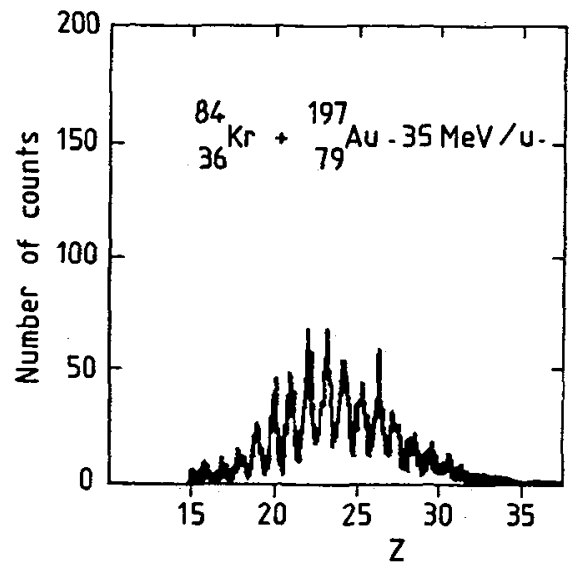

Fig. 2 - Atomic number distribution of the events in Fig. 1 .

the best tool to follow the evolution of the mechanism when starting from the lowenergy point of vue.

The reason why this is so is easy to understand. At low bombarding energy, two

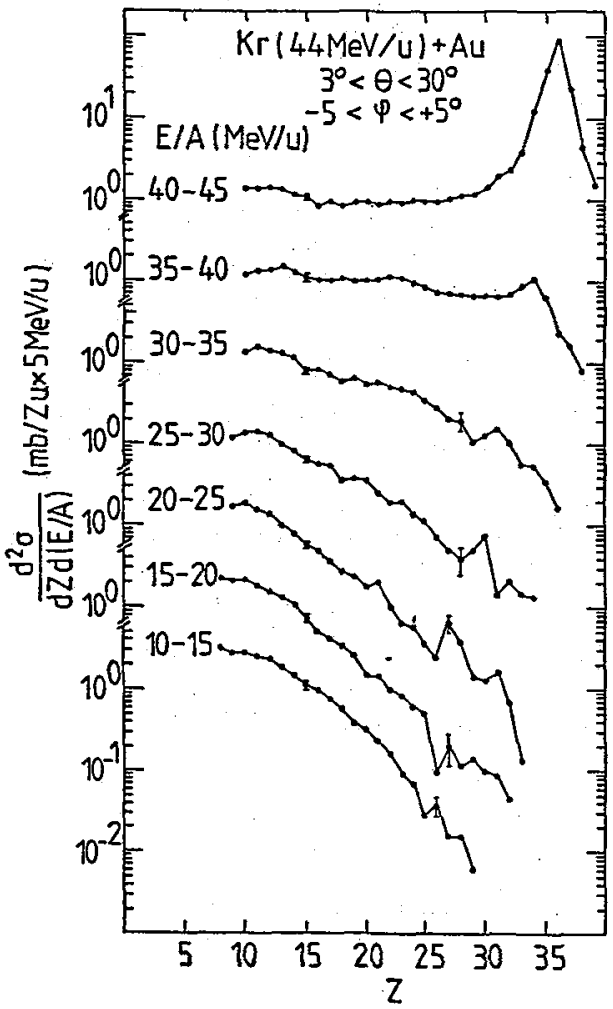
main mechanisms are observed in heavy ion reactions : fusion and deep inelastic collisions. Fusion is not seen for systems of total mass larger than $300 \mathrm{a} \cdot \mathrm{m} . \mathrm{u}$. (4). On the other hand, mass 100 ions are very stable against fission when compared to much heavier ones. They are therefore good projectiles to study deep inelastic reactions, and certainly also to follow the evolution of this mechanism in the transition region opened by Ganil.

Fig.3 -Atomic number distributions integrated over the angular range reported in the figure (from Ref.3). 
II a - DEEP INELASTIC COLLISIONS AT LOW BOMBARDING ENERGIES

Deep-inelastic collisions are quite fascinating. We have learned through them that two heavy nuclei can stick together for a rather long time : $10^{-20}$ sec or so. During this time, they exchange many nucleons, transform as much kinetic energy as possible into excitation energy, equilibrate their temperatures and deform considerably before reseparating; these are the features, among all those which have been studied, which will retain our attention in the following.

II $\mathrm{b}$ - THE NUCLEON EXCHANGE PROCESS UP TO $20 \mathrm{MeV} / \mathrm{u}$

The evolution of the nucleon exchange process has been studied by Gralla et al. (5). These authors have measured the $92 \mathrm{Mo}+92 \mathrm{Mo}$ and $100 \mathrm{Mo}+100 \mathrm{Mo}$ reactions between 12 and $18.8 \mathrm{MeV} / \mathrm{u}$. The fact that the two ions are identical allows to test if the reaction is still of two-body nature (see section II e). It is then possible, by measuring the time of flight of both reaction partners, to obtain primary charge and mass distributions, and hence moments for them which are little disturbed by the light particles evaporation.

Charge and mass varlances increase with increasing energy loss : this proves that, when the two nuclei come to contact, the potential barrier between them vanishes, a window opens and the nucleons, through the Fermi motion, pass this window in both directions $(\mathrm{Fig}, 4)$. It has be shown (6) that $\sigma_{\AA}^{2}$ is approximatively equal to
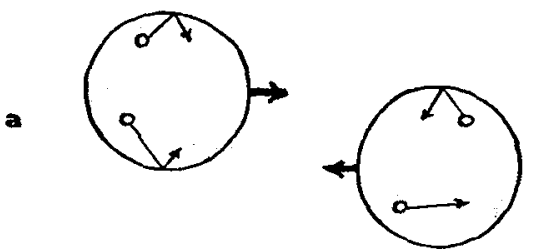

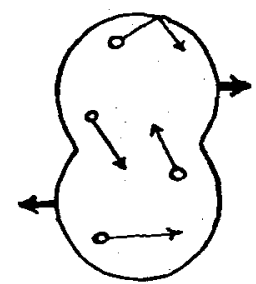

Fig.4 - Nucleon motion before the deep inelastic reaction (a) and during it (b).

the total number of nucleons which have passed the window.

Fig.5 shows that tremendously high values of $\sigma_{\mathrm{A}}^{2}$ are observed at $18.8 \mathrm{MeV} / \mathrm{u}:$ they indicate that more than 1000 nucleons can be exchanged.

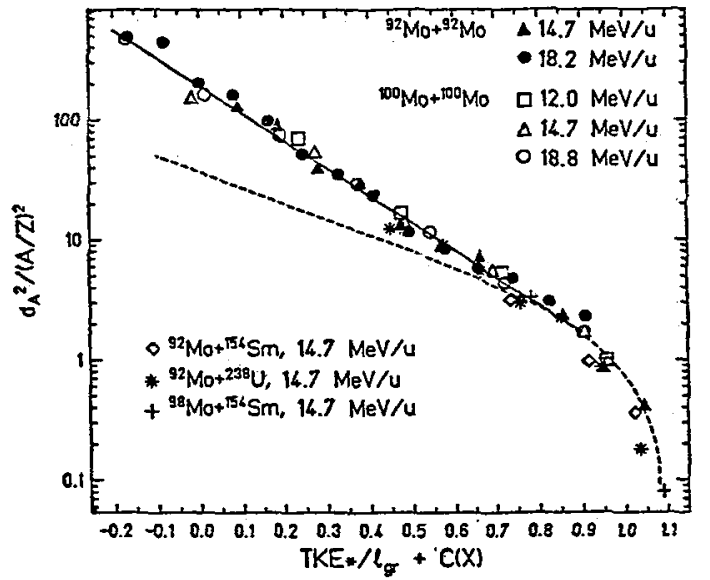

Fig. 5 - Mass variances of $[$ in units of $\left.(A / Z)^{2}\right]$ as a function of $E_{\text {Ktot }} / 2+C(x)$ of all measured systems. The system-dependent shift $c(x)$ allows for a direct comparison between these. (From Res.5). 
The increase of maximum $\sigma_{\mathrm{A}}^{2}$ with the bombarding energy may indicate an increase of the interaction time. In Ref.5) it is suggested that it is due, rather, to the increase of the temperature of the dinuclear system. This assumption is based on a universal law which has been shown to be followed by all systems at low bombarding energy (7). When extrapolated to $18.8 \mathrm{MeV} / \mathrm{u}$, it is still followed by the Mo + Mo systems (Fig.5) : this proves that the mechanism has not changed in its nature.

The consequence of this large number of nucleon exchanges is shown in Fig.6:

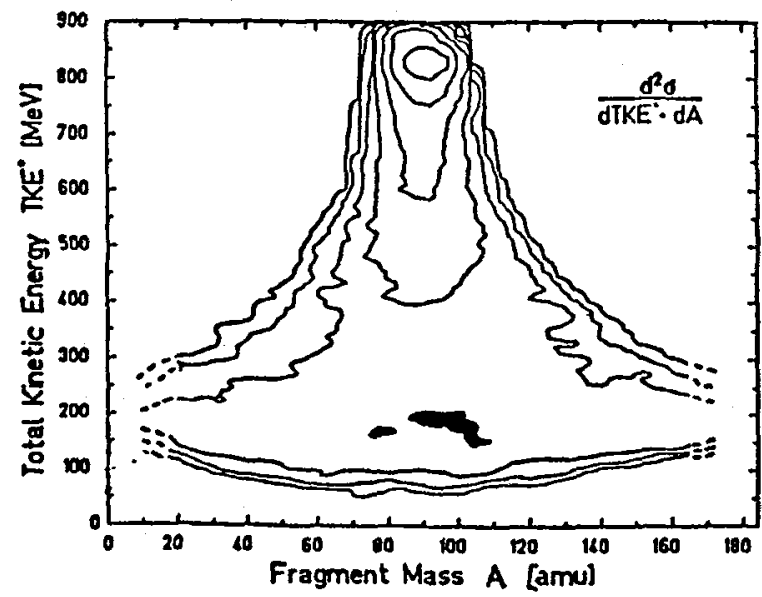

Fig.6 - Diffusion-plot of binary products formed in the reaction 92 MO +92 MO at $18.2 \mathrm{MeV} / \mathrm{u}$; dashed contour lines denote areas where the yield is affected by geometrical cuts (From Re\{.8).

very broad mass distributions are observed in the fully damped region. They extend to vanishing values of the mass : this can be interpreted as a kind of "slow fusion" which is achieved through the sequential transfer of all nucleons from one nucleus to the other. This mechanism appears, however at temperatures where the system may no more be stable against multifragmentation (see section II e). But first, we shall examin some deviations from the classical deep inelastic process which are already seen at $\mathrm{E} / \mathrm{A}<20 \mathrm{MeV} / \mathrm{u}$.

\section{II $c$ - THE ONSET OF THREE-BODY MECHANISMS}

Three fragments-events can be observed in a heavy ion reaction either after a sequential fission or after the fast.break-up of one of the partners. In the first case, the mechanism is still of two body nature, like a deep inelastic collision (Fig.7). In the second case, the process is a fast three-body mechanism, 1ike those which are observed at high bombarding energies.

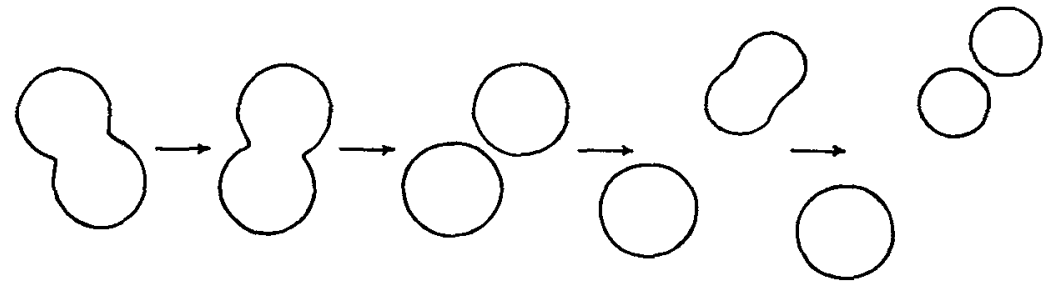

Fig.7 - Schematic picture of a deep inelastic callision followed by the fission of one partner.

This simple picture can be complicated by several factors. First, nuclei are strongly deformed in a damped collision : this. Is seen in Fig.6, where one observes events having a TKE much lower than the Coulomb energy of two spheres. Because of these deformations, it is quite posilble that a neck forms in one of the partners (or in both) : different scission processes can therefore be imagined (Fig.8). 
Second, deformations modify the potential energy and can induce thereby strong mass drifts (9) so that final masses do not allow to identify unambiguously the partners of the first or second scission. Last, strong final-state coulomb interactions modify the energy and angular correlations between the fragments.

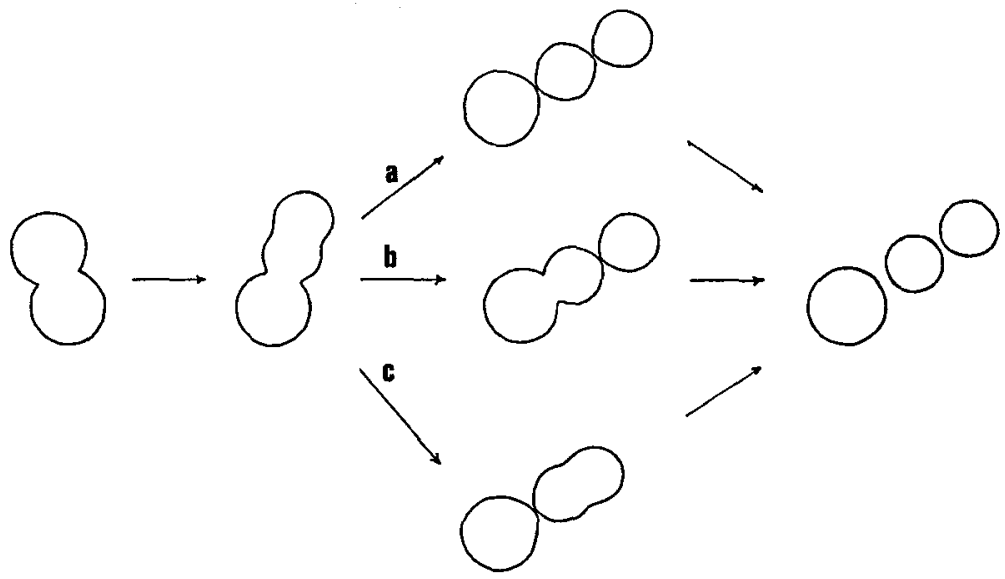

Fig.8 - Different scission processes leading to a three-body final state

The first indication for a three-body break-up was observed in the ${ }^{86} \mathrm{Kr}+{ }^{166} \mathrm{Er}$ reaction at $12.1 \mathrm{MeV} / \mathrm{u}(10)$. This phenomenon was investigated in great detail in the ${ }^{84} \mathrm{Kr}+166_{\mathrm{Er}}$ and $129 \mathrm{Xe}+122 \mathrm{Sn}$ reactions at nearly the same energy (11). A strong yield of three-body events was observed. It was shown that they are produced in a mechanism intermediate between the sequential fission and the fast break-up : indeed, a time scale of $1 \cdot 10^{-21} \mathrm{sec}$ between the consecutive scissions was established. This time is large enough to consider the mechanism to be a sequential one, and sma11 enough to allow a Coulomb final-state interaction to show up.

The effects of this interaction were studied in Ref.11) as a function of the azimuthal angle $\phi_{f}$ : the relative velocity, the yield and the mean value of the fission fragment-mass distribution fluctuate.

These features show that we are no more dealing with an equilibrated, sequential fission following a damped collision. It is also not a fast break-up of the participant-spectator type seen at much higher energies. Indeed, Fig. 9 shows that three2-BODY TOTAL KINETIC ENERGY (MeV)

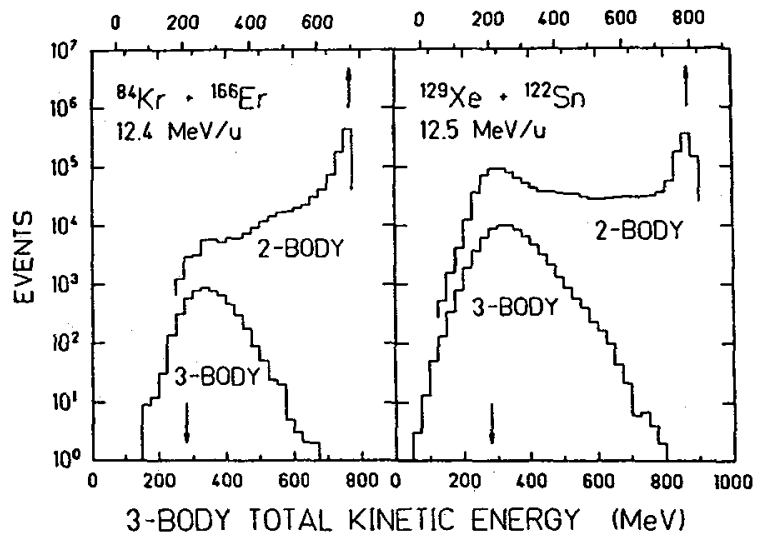

Fig. 9 - Mass - and angle-integrated total kinetic energy distributions for exclusive binary and ternary events in their true relative ratio. To facilitate comparison, the energy scales for the ternary events are shifted relative to those for the binary ones by the additional coulomb energy released in a three-particle decay. (From Ref.11). 
body events are associated with the largest energy losses, i.e. with the largest deformations. From this, we may conclude that deformability can "accelerate" the second scission.

Recently, a long time scale between the two scissions has been found in the $35 \mathrm{Cl}+\mathrm{Ta}$ reaction at $20 \mathrm{MeV} / \mathrm{u}$ (12). The low deformability of $3{ }^{\mathrm{C} 1}$, when compared to $129 \mathrm{Xe}$, may explain it.

\section{II d - PARTICIPANTS AND SPECTATORS}

It is we11-known, at low bombarding energy, that two partners of a damping collision tend to share their excitation energy so as to equilibrate their temperatures. At high energy, on the contrary, zones of low temperature (the spectators) coexist with zones of high one (the participants).

Temary reactions, like those we have seen in the preceeding section, may be a good tool to observe differences of temperatures between the three fragments : indeed, during the first dissipative step of the reaction, one fission fragment is closer to the contact zone than the other. The three cases of Fig. 8 correspond then to the creation of an independant fire-ball (a), partial fusion of the hot zone on the target (b) or on the projectile (c). Because mean field effects are still important at Ganil energies, the two last pictures are quite likely to be observed.

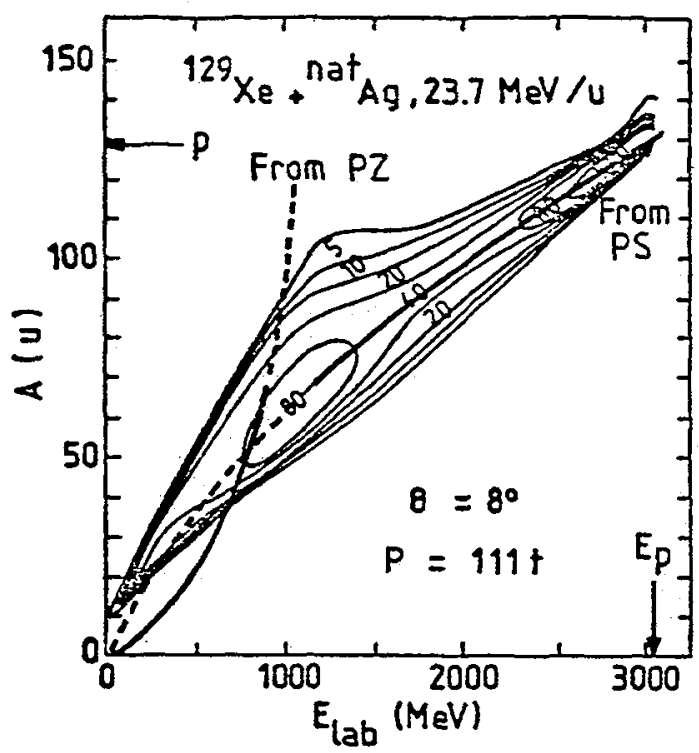

Fig.10 - Calculated correlation in the plane $(E, A)$ for the $X e+A g$ system, associated with the second model. Comparison with the results is done. (From Re6.131.

Various data confirm such ideas. However, the models which have been used to analyze them present some definite differences with those of Fig.8. First, complete energy damping is no more reached (12) (see also section II e). Second, deformations are not considered, but the existence of a localized zone of participant nucleons is a crucial ingredient of the models.

As an example, Fig. 10 shows the correlation in the (E,A) plane for single events measured in the $129 \mathrm{Xe}+\mathrm{Ag}$ reaction at $23.7 \mathrm{MeV} / \mathrm{u}$ (13). The data have been analysed in the frame of three different models, which are sketched in Fig.11. In all three models, the participant zone (PZ) fuses with the projectile spectators (PS). In model 1 , it reseparates before thermal equilibrium has been reached. In model 2 , equilibrium is reached for the temperature, and in model 3 even for the mass assymetry. Grossly speaking, we may think at the second stage of the reaction as a deep inelastic reaction between the cold PS and the hot PZ (14). Fig. 10 shows that model 2 fits reasonably well the data when the additional assumption is made that PS as we1l as PZ disappear through multifragmentation when their temperature is higher than $6 \mathrm{MeV}$. 
Model $\mathrm{I}$ is found to better describe the ${ }^{84} \mathrm{Kr}+98 \mathrm{Mo}$ and ${ }^{84} \mathrm{Kr}+197 \mathrm{Au}$ data (15) (Fig.12). To explain this observation, it was speculated that calefaction, a concept wel1 known in condensed matter physics, can be applied also to nuclear physics (15).

MODEL
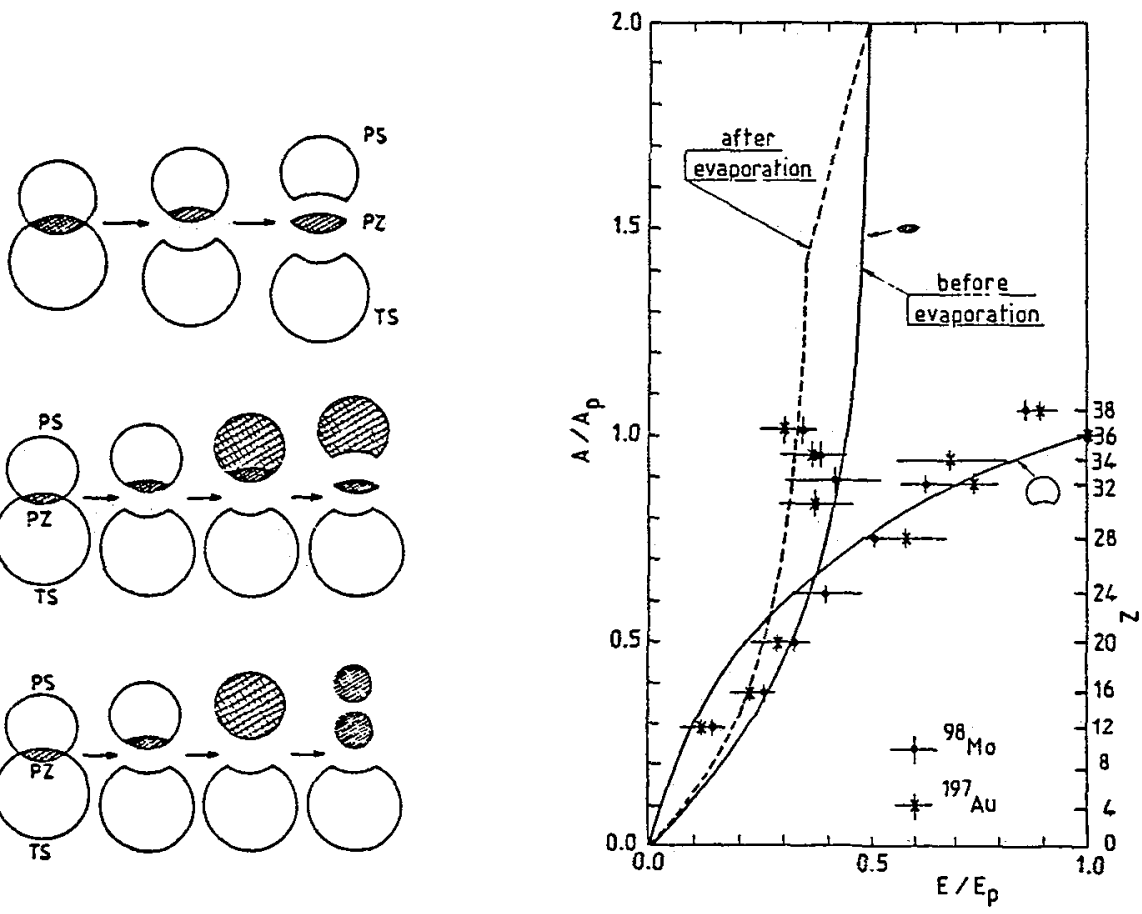

Fig.11 - Schematic representations of the three interaction scenarias described in the text. (From Ref. 13).

Fig.12 - A comparison between the experimental data and the calculated correlation for scenario 1 of figure 11 lcalefaction in the PS + PZ system). (From Ref.15).

II e - HIGH TEMPERATURES AND MULTIERAGMENTATION

Collisions between identical ions allow to test if the mechanism is of two-body nature : in this case, indeed, primary charge or mass distributions must remain centered at projectile value. Fig. 6 shows that, even for the largest energy losses, this is fairly checked in the $92 \mathrm{Mo}+92 \mathrm{Mo}$ at $18.2 \mathrm{MeV} / \mathrm{u}$ when coincidences are selected by conditions of coplanarity and center-of-mass colinearity. This ensures that, during the selected collisions, the observed kinetic energy loss of over $650 \mathrm{MeV}$ is transformed into excitation energy. The dinuclear system reaches thereby temperatures of more than $5 \mathrm{MeV}$. This is confirmed in Fig. 13 by the good agreement between temperatures calculated from the kinetic energy loss and those measured through the slope of evaporated proton energy spectra (8).

Mass 100 nuclei deexcite preferential1y by light particle evaporation. When the bombarding energy attains $20 \mathrm{MeV} / \mathrm{u}$, one can estimate that up to $30 \%$ of the total mass is evaporated in fully damped reactions. This rate would of course increase with the bombarding energy if full damping can still be reached.

The survival of full damping could be hindered due to various reasons. For example, when the velocity of the ions becomes greater than the Fermi velocity, the flux of nucleons through the window (see section II a) may drop. On the other hand, two body reactions may completely disappear, either through pre-compound particles emission, or the formation of separated zones of participant and spectator nucleons ( see section II d). 
Another mechanism may put an end to the increase of energy deposit during a heavy ion reaction. Indeed, multifragmentation has recent1y been predicted to occur when the temperature of a nucleus attains about $6 \mathrm{MeV}$ (16).

Experimental hints for this mechanism are based on the observation of intermediate mäss fragments in various experiments. Almost all data in this field are inclusive : quite few coincidence measurements have been reported and only at $\mathrm{E} / \mathrm{A} \leq 20 \mathrm{MeV} / \mathrm{u}$ (12). At Ganil, inclusive fragment-measurements have been performed for several $35 \mathrm{MeV} / \mathrm{u} \mathrm{Kr}$-induced reactions : on $27 \mathrm{Al}$ (17), $93_{\mathrm{Nb}}$ (18) and $\mathrm{Au}(3,19)$. While, in the first reaction, an equilibrated composit system seems to have been formed (17), the two others reveal the coexistence of different mechanisms. This is illustrated in Fig.14 where two groups of fragments are observed at angles smaller or larger than the grazing angle (see also Fig.3).

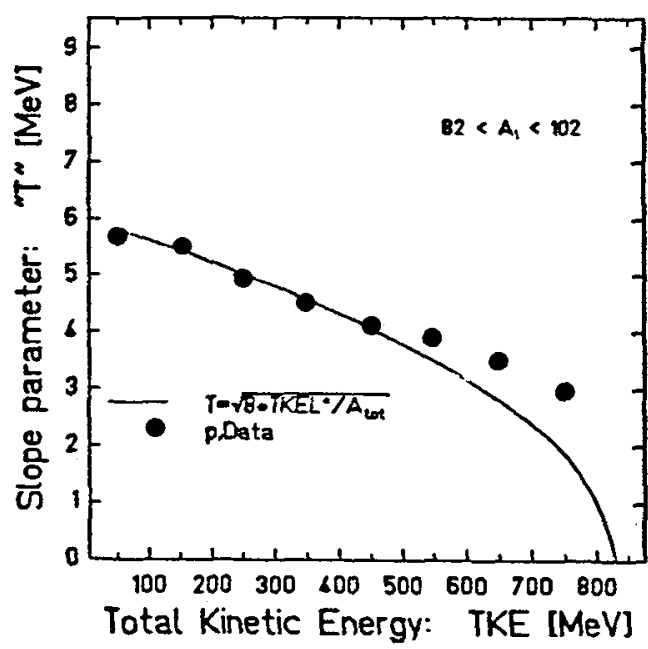

Fig. 13 - "Slope parameter" $T$ resulting from the fits to the distributions of the measured proton evaporation spectra.

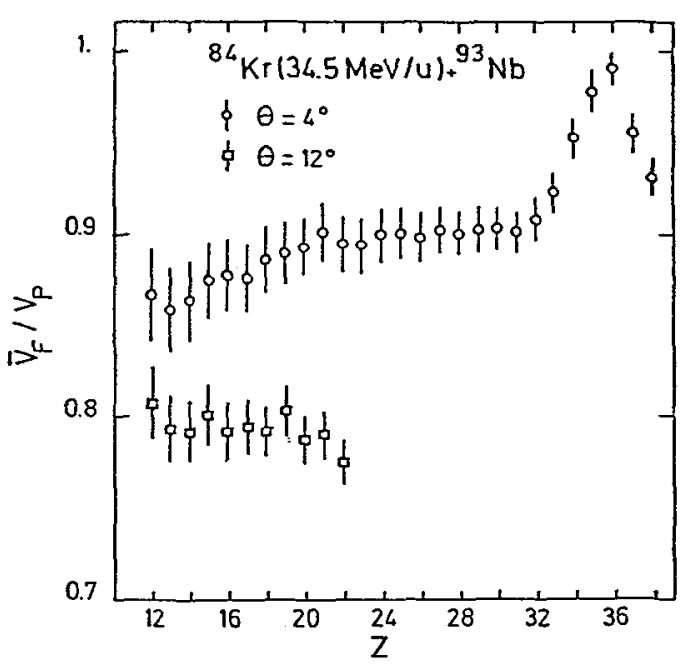

Fig. 14 - Mean velocities of fragments compared to projectile velocity $V_{p}$ (Fram Ref. 18).

More recent1y, coincidences between $\mathrm{z}=8-36$ fragments emitted in forward direction $\left(\theta=3^{\circ}\right.$ to $\left.30^{\circ}\right)$ have been measured for the $\mathrm{Kr}+$ Au reaction at 35 and $44 \mathrm{MeV} / \mathrm{u}$ (3). In Fig. 15 is shown the $\mathrm{E}_{\mathrm{rel}}^{*}$ spectrum. $\mathrm{E}_{\mathrm{re} 1}^{*}$ is the difference between the relative energy of the two fragments and their Coulomb repulsion. The absence of counts below $E_{r e 1}^{*} \approx 0$ shows that the fragments are not emitted sequentially by a single nucleus. Rather, it appears that they are either emitted in close contact $\left(E_{r e 1}^{*} \simeq 0\right)$ by the same source, or that they originate from two sources $\left(E_{r e 1}^{*}>0\right)$, the relative velocity of which increases with the bombarding energy.

The fragment velocity spectra corresponding to these two kinds of coincidences are shown in Fig. 16. Three components appear : fast fragments $\left(V / V_{p} \sim 0.9\right)$ are in coincidence with slow ones $\left(V / V_{p}<0.7\right)$, while the fragments with $E_{\text {ret }}^{*} \simeq 0$ have a broad velocity spectrum with a maximum around $V / V_{p}=0.6$.

The fast-slow coincidences (Fig.16a) can be interpreted in the framework of the ablation-abrasion model (20) : projectile spectators, whose velocity has been slowed down to $0.9 \mathrm{~V}$ by the separation of the participant nucleons, are detected in coincidence with fragments emitted by the participant zone. The velocity of this later source is predicted to be equal to $0.35 \mathrm{~V}_{\mathrm{p}}$, due to the fact that projectile and target do not contribute equally to $1 \mathrm{t}$.

The source with velocity $0.6 \mathrm{~V}_{\mathrm{p}}$ evidenced in the $\mathrm{E}_{\mathrm{rel}}^{*} \simeq 0$ coincldences (Fig.16b) is not predicted in this model. Therefore, one can try to interprete the whole set of data with the mechanlsms sketched in Fig.11. When, in the first step of any of the three models, as much as 50 nucleons are transfered from the target on the projectile, the velocity of this composite is equal to about $0.6 \mathrm{~V}_{\mathrm{p}}$. If the energy is 
shared over all the nucleus (model 2 or 3), its temperature attains 8.5 MeV. If this hot nucleus undergoes multifragmentation, it will emit fragments which may be detected in the $E_{r e 1}^{\star} \simeq 0$ coincidences. Inversely, one can imagine that the nucleons are transfered on the target. More than 30 nucleons have to be transfered this way to accelerate the target-composite sufficiently to allow fragments emitted by it to be detected in the set-up. It happens that, at the same time, its temperature becomes larger than $6 \mathrm{MeV}$ : it may therefore emit fragments which we detect as slow ones, in coincidence with the remainder of the projectile (Fig.16a).
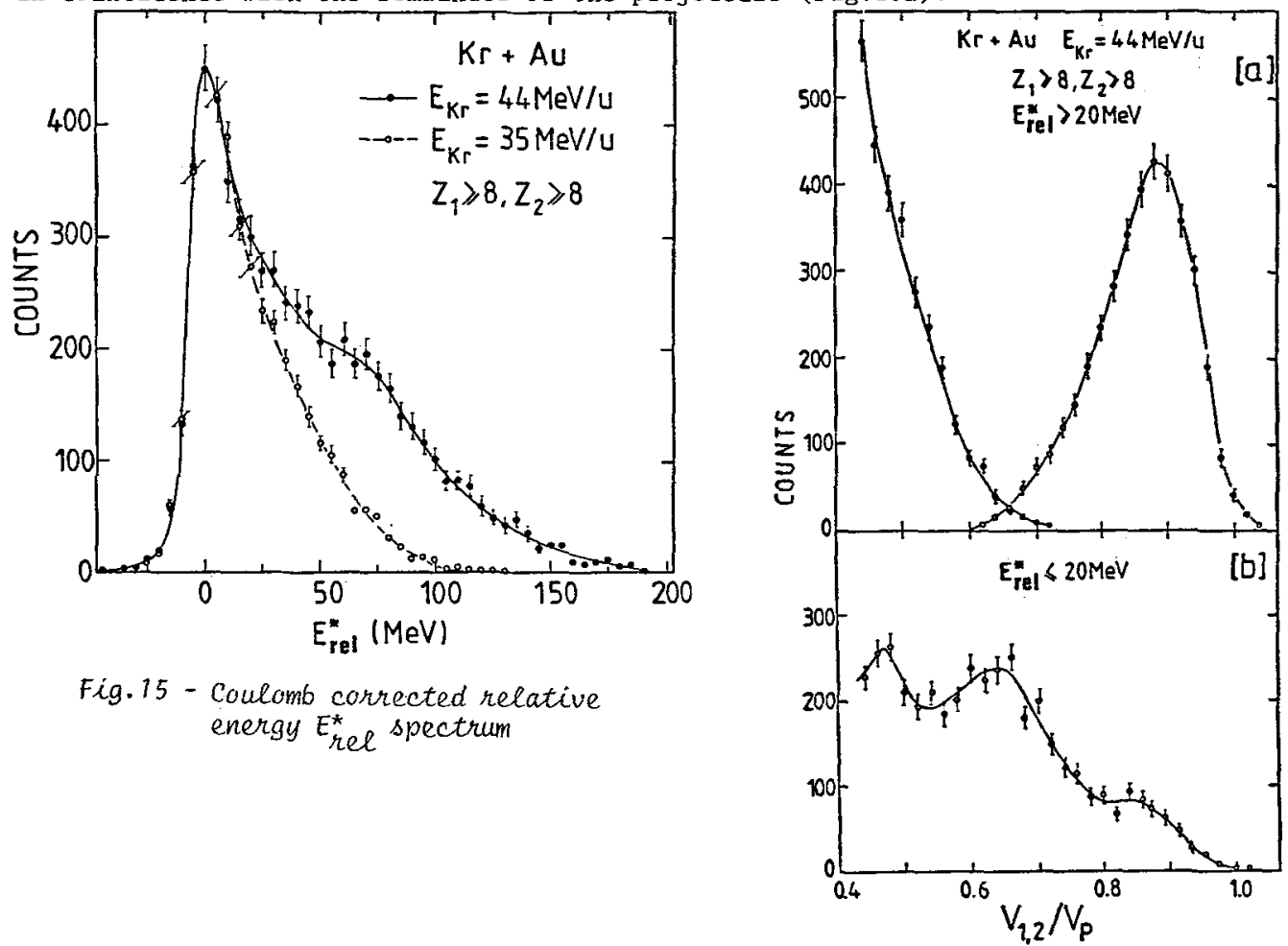

Fig. 15 - Coulomb corrected relative energy E $E_{\text {rel }}^{*}$ spectrum

Fig.16 - Velocity spectra of fragments detected in selected coincidences.

Linear momentum transfer, as we see, is a crucial quantity to explain these data. The underlying mechanism may be the interaction between the participant zone and one of the two spectators zones like in Fig.11, but also multinucleon transfer or perhaps even a dissipative collision like in $\mathrm{F} 1 \mathrm{~g} .8$. Wh1le kinematics are insensitive on the choice of the model, temperatures and therefore the rate of evaporated particles depend strongly on it. This fact was used in Refs.13 and 15 to distinguish between the models in Fig.11. At bombarding energies as high as $44 \mathrm{MeV} / \mathrm{u}$, this is no more possible. Coincidences between heavy fragments have the great merit to select different types of collisions, but essentially collisions in which high temperatures are attained. Light particles emitted during these collisions have to be detected to allow a direct measure of the temperature (Fig.13) and an estimate of the primary masses. Heavy nuclei produced by the sequential fission (Fig.7) of the target have already been measured; preliminary data show that most of them are detected in coincidence with a quas1-projectile, and not with the above described coincident fragments, confirming that these are produced in very violent collisions (19). 


\section{III - CONCLUSION}

Deep inelastic reactions have been observed between mass 100 ions up to $20 \mathrm{MeV} / \mathrm{u}$. Deformations, however, increase the fission probability of the partners and shorten their life-time, giving rise to a cross section for a non-equilibrated three body mechanism. This mechanism, which has a $10^{-21} \mathrm{sec}$ characteristic time scale at $12 \mathrm{MeV} / \mathrm{u}$, is nethertheless quite different from fast break-up.

Above $20 \mathrm{MeV} / \mathrm{u}$, multifragmentation sets probably in because the temperature of the partners can exceed $6 \mathrm{MeV}$. Direct measurement of temperatures close to $6 \mathrm{MeV}$ in a deep inelastic reaction has been realised slightly below $20 \mathrm{MeV} / \mathrm{u}$ by selecting two body events in collisions between identical ions. Such an experiment is still possible at a somewhat higher energy, and may allow a measure of the limiting temperature for multifragmentation.

Around $25 \mathrm{MeV} / \mathrm{u}$, participant-spectator models including collective nuclear meanfield effects have been used to interprete singles data. They showed that concepts, borrowed from condensed matter physics, may be applied to nuclei. Exclusive experiments are now needed to confirm these ideas.

Below $35 \mathrm{MeV} / \mathrm{u}$, Coulomb final state interactions may jumble somewhat the correlations measured in fragment-coincidences. At $44 \mathrm{MeV} / \mathrm{u}$, on the contrary, it has been possible to separate companents corresponding to different sources. OnIy two of them can possibly be understood in the frame of a participant-spectator model. All three can be explained by mechanisms involving a large energy damping. More investigations are needed to elucidate the nature of this mechanism.

\section{ACKNOWLEDGEMENTS}

Thanks are due to all my colleagues at Strasbourg, Caen, Saclay and Darmstadt for helpfull discussions. In particular, A. Gobbi, K.D. Hildenbrandt and Ch. Ngo have provided me with data prior to publication.

\section{REFERENCES}

1) D. Dalili et a1., Z. Phys. A316 (1984) 371.

2) V. Borel et al., Z. Phys. A134 (1983) 191.

3) A. Kamili, Ph.D. Thesis, CRN Strasbourg and University Louis Pasteur (1986).

4) M. Lefort, C. Ngo, J. Peter and B. Tamin, Nuc1. Phys. A216 (1973) 166.

5) S. Gra1la et a1., Phys.Rev.Lett. 54 (1985) 1898.

6) G. Rudo1f, Z. Phys. A320 (1985) 375.

7) H.J. Wo1lersheim et aI., Phys. Rev. C25 (1982) 338.

8) N. Herrmann, Diplom, University of Müster, (1984)

9) G. Guarino et a1., Nucl. Phys. A424 (1984) 157.

10) A. Olmi et al., Phys. Rev. Lett. $44(1980) 383$.

11) P. Glässel, D. von Harrach, H.J. Specht and L. Grodzins, Z. Phys. A310 (1983) 189.

12) M.J. Mùrphy et a1., Phys. Rev. Lett. 53 (1984) 1543.

13) 0. Granier et al., Contribution to the XXIV th International Winter Meeting on Nuc1. Phys., Bormio (1986).

14) C. Ngo, private communication.

15) D. Dalili et al, Z. Phys. A320 (1985) 349.

16) J. Bondorf et al.; Nucl. Phys. A444 (1985) 460.

17) W. Mittig et a1., Phys, Lett. $154 \mathrm{~B}$ (1985) 259.

18) J.L. Charvet et a1., Z. Phys. $\overline{\mathrm{A} 321}$ (1985) 701.

19) B. Botshu, Thèse de $3 e$ cycle, L.P.C. Caen and University of Caen (1985)

20) R. Dayras, private communication. 